\title{
Hypertensive States during Labor and Puerperium
}

\author{
R Illia ${ }^{1 *}$, Lobenstein $\mathrm{G}^{2}$, UrangaImaz $\mathrm{M}^{2}$, Manrique $\mathrm{G}^{2}$, Fiameni $\mathrm{F}^{2}$, Guallan $\mathrm{F}^{2}$ and Ceretti $\mathrm{S}^{3}$ \\ ${ }^{1}$ Professor of Obstetrics at Medicine School, Buenos Aires University, Argentina \\ ${ }^{2}$ Obstetrics Service, Hospital Aleman, Argentina \\ ${ }^{3}$ Resident of Obstetrics Service, Hospital Aleman, Argentina
}

Submission: December 11, 2017; Published: February 09, 2018

*Corresponding author: Illia R, Department of Obstetrics, Buenos Aires University, Hospital Alemán, Argentina, Email: rhillia@gmail.com

\begin{abstract}
Hypertension complicating pregnancy, including during puerperium, is defined according American College of Obstetricians \& Gynecologists (ACOG) as systolic blood pressure $140 \mathrm{~mm} \mathrm{Hg}$ or greater and/or diastolic blood pressure $90 \mathrm{~mm} \mathrm{Hg}$ or greater on 2 or more occasions at least 4 hours apart. The objective was evaluate a series of patients who were normotensive during pregnancy but presented several kind of gestational hypertensive disorders during labor or during puerperium. This is a retrospective series of cases affected by several kind of hypertensive disease in immediate postpartum period, is almost impossible to implement a control group at least the patients were randomized to be treated with one or other antihypertensive drug. So, the study has the pitfalls of the retrospective series, but there are so few articles with real cases of hypertension illness in puerperium that were normotensive during pregnancy, that this series of patients may contribute to the clinicians handling pregnancies to increase the suspicion of the hypertensive disease also can develop during puerperium and is better for the patients to be alert considering this possible complication.
\end{abstract}

Keywords: Hypertensive disease; Puerperal hypertension; Maternal mortality

\section{Introduction}

Hypertension complicating pregnancy, including during puerperium, is defined according American College of Obstetricians \& Gynecologists (ACOG)as systolic blood pressure $140 \mathrm{~mm} \mathrm{Hg}$ or greater and/or diastolic blood pressure $90 \mathrm{~mm} \mathrm{Hg}$ or greater on 2 or more occasions at least 4 hours apart. Severe hypertension is defined as systolic blood pressure $160 \mathrm{~mm}$ $\mathrm{Hg}$ or greater and/or diastolic blood pressure $110 \mathrm{~mm} \mathrm{Hg}$ or greater on 2 or more occasions repeated at a short interval [1]. Is important to take in account that only one diastolic pressure value of $110 \mathrm{~mm} \mathrm{Hg}$ or more, is diagnosis of hypertensive emergency and it should promote not only a close control of the situation but take the right measures to prepare the patient and her fetus for a potential delivery for maternal indication. It is wise not to take for granted that once delivery is done, the patient is not going to develop increased blood pressure. After to confirm the hypertensive state of the patient, she will go through the Classification of Hypertension in Pregnancy to define the therapeutic strategies. A very particular picture is those patients who are normotensive during pregnancy, but become hypertensive during labor or during postpartum period. There is not much written evidence about this weird situation, but it could become seriously enough to affect the mother and to present fetal or neonatal complications that appear in unexpected way and lend support to the recommendation of close control of arterial blood pressure in immediate and no immediate puerperium.

\section{Objective}

To evaluate a series of patients who were normotensive during pregnancy but presented several kind of gestational hypertensive disorders during labor or during puerperium.

\section{Material and Methods}

During the period between January of 2014 and January of 2017 we assisted 4230 deliveries at Hospital Alemán. We selected the group of patients who developed diverse kind of hypertensive disorders during labor and puerperium had been normotensives during their pregnancy. The classification of the patient as hypertensive was done according the guidelines of ACOG [2] (systolic blood pressure $140 \mathrm{~mm} \mathrm{Hg}$ or greater and/ or diastolic blood pressure $90 \mathrm{~mm} \mathrm{Hg}$ or greater on 2 or more occasions at least 4 hours apart. Severe hypertension is defined as systolic blood pressure $160 \mathrm{~mm} \mathrm{Hg}$ or greater and/or diastolic blood pressure $110 \mathrm{~mm} \mathrm{Hg}$ or greater on 2 or more occasions repeated at a short interval). The patients were studied and classified by laboratory tests, blood pressure values, need of antihypertensive drugs (one or more), the responsiveness to this 
drugs, the tendency to increase or decrease the blood pressure values, the rate of complications and their severity, the way and time of pregnancy finalization and perinatal information.

\section{Results}

During this 36 month period were found 19 patients who became hypertensive according the definition (ACOG) [2] $(0.44 \%$ of the total deliveries). The average age was 30.9 years (19-41). The percentage of first pregnancies was 52.63\% (n: 10 cases) have been the rest ( 9 cases) with previous pregnancies. The mean of weight increase during pregnancy was $18.8 \mathrm{Kg}$ (between 12 and $28 \mathrm{Kg}$ ). The mean of systolic blood pressure during pregnancy was $108 \mathrm{mmHg}(95-108 \mathrm{~mm} \mathrm{Hg})$ and the mean of diastolic blood pressure during pregnancy was $68 \mathrm{~mm} \mathrm{Hg} 60$ $75 \mathrm{~mm} \mathrm{Hg}$ ). The percentage of patients with positive hypertensive response was $31 \%$ without have become hypertensive at any point of pregnancy. There were a $57.89 \%$ of cesarean sections (CS) (11 cases) and $42.10 \%$ of vaginal deliveries ( 8 cases). Of the ten cases that finalized in CS, one was intrapartum (5.26\%), 7 cases were scheduled (because hypertensive disease) (36.84\%) and there were 3 cases of emergency CS (15.78\%) because of seriousness of the hypertensive disease or lack of response to the antihypertensive treatment. The mean of birth weight of newborns was 3.371g (2.575-4.400g). The mean of gestational age established by physical examination of the newborns was 38.4 week's (36-40). The time elapsed between delivery and the patient became hypertensive was between 0 and $144 \mathrm{hs}$ with a mean of $38 \mathrm{hs}$. The higher value of hypertension occurred between 2 and $154 \mathrm{hs}$ with a mean of 59hs. The mean of higher systolic value was $162 \mathrm{~mm} \mathrm{Hg}(110-190 \mathrm{~mm} \mathrm{Hg})$ and the mean of higher diastolic blood pressure was $103 \mathrm{~mm} \mathrm{Hg}$ (90-120mm $\mathrm{Hg}$ ). The patients were classified according the blood pressure values and laboratory tests in: pregnancy induced hypertension $52.63 \%$ (10 cases), preeclampsia in $42.10 \%$ (8 cases) and Hellp syndrome in $5.26 \%$ ( 1 case). The $68.42 \%$ of cases required antihypertensive drugs (13 cases). In 6 cases it was necessary only one drug $(46.15 \%$ of medicated patients and $31.57 \%$ of the total population studied. In 5 cases it was necessary two drugs (38.46\% of medicated patients and $26.31 \%$ of total). As we can observe in the Table 1 , the most common drugs used were: methyldopa, amlodipine, nifedipine and labetalol, alone or combined. In two cases (10.52\%) we injected low molecular weight heparin (LMWH) as venous and lung thrombosis prevention because one case was an obese patient and another the patient was older than 35 years old. The mean time until obtain a regulation of blood pressure was 4.3 days (1-8). As we can deduce, luckily our patients in this series did not developed neither neurological affection nor seizures (eclampsia).

\section{Table 1:}

\begin{tabular}{|c|c|c|}
\hline \multicolumn{3}{|c|}{ HTA Puerperal } \\
\hline Period & 36 months & \\
\hline $\mathrm{N}$ & 19 & $0.44 \%$ \\
\hline deliveries & 4230 & $100 \%$ \\
\hline Age $\%$ & 30,9 & $19-41$ \\
\hline Pregnancies \% & 1,9 & 01 a 7 \\
\hline First pregnancy & 10 & $52.63 \%$ \\
\hline $20+$ & 9 & $47.37 \%$ \\
\hline \multirow{3}{*}{ Abortions } & 0 & $14-73.68 \%$ \\
\hline & 1 & $2-10.52 \%$ \\
\hline & 4 & $1-5.26 \%$ \\
\hline \multirow{3}{*}{ Deliveries } & 0 & 16- \\
\hline & 1 & $1-5.26 \% \%$ \\
\hline & 2 & $2-10.52 \%$ \\
\hline \multirow{3}{*}{ Cesarean Sections } & 0 & $15-78.94 \%$ \\
\hline & 1 & $3-15.78 \%$ \\
\hline & 2 & $1-5.26 \%$ \\
\hline Start pregnancy weight $\%$ & 59,5 & $44-80$ \\
\hline Increase of weight & 18,8 & 12 a 28 \\
\hline Medication & 3 de 17 & Fe - T4 - Ceftriaxona \\
\hline Sistolic blood pressure\% & 108 & $95-125$ \\
\hline Diastolic blood pressure $\%$ & 68 & $60-75$ \\
\hline Hipertensive response & $31 \%$ & \\
\hline GA to delivery $\%$ & 39 & $36-41$ \\
\hline \multirow{2}{*}{ Way to deliver } & IPCS & $1(5.26 \%)$ \\
\hline & SCS & $7(36.84 \%)$ \\
\hline
\end{tabular}


Journal of Gynecology and Women's Health

\begin{tabular}{|c|c|c|}
\hline & ECS & $3(15.78 \%$ \\
\hline & FD & $1(5.9 \%)$ \\
\hline & SD & $5(29,4 \%)$ \\
\hline & VD & $2(11,8 \%)$ \\
\hline \multirow{2}{*}{ Sex } & $\mathrm{F}$ & $12(63.15 \%)$ \\
\hline & M & $7(36.84 \%)$ \\
\hline Weight \% & 3371 & $2575-4400$ \\
\hline Gestational age by $\mathrm{PE}$ & 38,4 & $36-40$ \\
\hline Time tobecome hypertensive & $\% 38 \mathrm{hs}$ & $0-144 \mathrm{hs}$ \\
\hline High peak of BP & $59 \mathrm{hs}$ & $2-154 \mathrm{hs}$ \\
\hline Higher Systolic BP & 162 & $(110-190)$ \\
\hline Higher Diastolic BP & 103 & $(90-120)$ \\
\hline \multirow{3}{*}{ Hypertensive class } & HIE & $10(52.63 \%)$ \\
\hline & Preeclampsia & $8(42.10 \%)$ \\
\hline & HELLP & $1(5,26 \%)$ \\
\hline \multirow{13}{*}{ Antihypertensive drugs } & $13(68.42 \%)$ & \\
\hline & 1 drug & $6(46.15)-31.57 \%$ \\
\hline & 2 drugs & $5(38.46 \%)-26.31 \%$ \\
\hline & 2 methyldopa $500 / 8$ & \\
\hline & 1 amlodipine $6 / 12$ - MD 500/8 & \\
\hline & 1 labetalol 300/12 + nifedipine R 2/12 & \\
\hline & 1 labetalol 400/12 + amlodipine $5 / 24$ & \\
\hline & 1 labetalol 800/12 + amlodipine 5/12 & \\
\hline & 1 labetalol 300/12 + amlodipine 10/12 & \\
\hline & 1 Labetalol 100/12 & \\
\hline & 1 Labetalol 200/12 & \\
\hline & 1 Labetalol 300/12 & \\
\hline & 1 Labetalol 400/12 & \\
\hline Prevention of DVT & $2(10.52 \%)$ & Obese-older $35 \mathrm{Y}$ \\
\hline Time to control BP & 4,3 dias $\%$ & 1-8 días \\
\hline
\end{tabular}

GA: gestational age; IPCS: intrapartum cesarean section; SCS: scheduled cesarean section; ECS: emergency cesarean section; FD: forceps delivery; SD: spontaneous delivery; VD: vacuum delivery; BP: blood pressure; DVT: deep venous thrombosis; Y: years.

\section{Discussion}

This is one of the few publications with a series of cases affected of Puerperal Hypertension. We analyzed the outcomes of this patient, and one of the main conclusions is not to take for granted that once delivery is done, the risk to develop hypertensive disease disappear. On the other way round, in spite of the percentage of affected patients is low, they still can develop a serious and unexpected hypertensive disease. Sharma et al stated that women with severe hypertension sustained over 15 minutes during pregnancy or in the postpartum period should be treated with fast-acting antihypertensive drugs. Labetalol, hydralazine, and nifedipine are all effective for acute management, although nifedipine may work the fastest. In the case of hypertension persist, long acting drugs should be used. Labetalol may achieve control at a lower dose with fewer adverse effects [3]. Hypertensive diseases accounted for $15.5 \%(n=126)$ out of all maternal mortality in the series of Keskinkilic et al. [4]. They were the third most frequent cause among all causes and the 2nd among direct causes of maternal deaths. Sixty-one (48.4\%) cases were in severe preeclampsia or pre-existing hypertensive disorder with increased or/and superimposed proteinuria, $30.1 \%$ were in eclampsia, 9.5\% cases were diagnosed as Hellp syndrome, and $11.1 \%$ in previous hypertension associated to pregnancy, childbirth, and puerperium. Intracranial hemorrhage was the major final cause of death with a rate of $41.3 \%$ according these authors. In our series we did not have neurological compromise of our patients. It may be attributed to the seriousness of the hypertensive disease in this two different populations. Is important to take present the conclusions of Belfort et al. [5] about the regulation of brain blood pressure by middle cerebral artery to make a right diagnosis and treatment. According their study, we have to choose the right 
antihypertensive drug because the wrong drug can lead to the patient to develop eclampsia. According the study of Mcllroy et al. [6] the reversible cerebrovascular vasoconstriction syndrome is an uncommon condition that presents as severe headache and hypertension. In spite off the rate of headache during puerperium is low, it can produce or allow to suspect serious neurological damage. Similar conclusions were communicated by Rezai et al. [7] in case of HELLP syndrome and Sibai et al in hypertensive disease. Also, Brousseau et al. [8] insist about the importance of the puerperal control of the blood pressure. During breast feeding, labetalol, methyldopa and nifedipine or amlodipine are safe antihypertensive drugs to handle arterial hypertension [9]. This is a retrospective series of cases affected by several kind of hypertensive disease in immediate postpartum period, is almost impossible to implement a control group at least the patients were randomized to be treated with one or other antihypertensive drug. So, the study has the pitfalls of the retrospective series, but there are so few articles with real cases of hypertension illness in puerperium that were normotensive during pregnancy, that this series of patients may contribute to the clinicians handling pregnancies to increase the suspicion of the hypertensive disease also can develop during puerperium and is better for the patients to be alert considering this possible complication [10].

\section{References}

1. Sharma KJ, Kilpatrick SJ (2017) Postpartum Hypertension: Etiology, Diagnosis, and Management. Obstet Gynecol Surv 72(4): 248-252.
2. (2017) Emergent therapy for acute-onset, severe hypertension during pregnancy and the postpartum period. Committee Opinion No. 692. American College of Obstetricians and Gynecologists Obstet Gynecol 129: e90-e95.

3. Sharma KJ, Kilpatrick SJ (2017) Postpartum Hypertension: Etiology, Diagnosis, and Management. Obstet Gynecol Surv 72(4): 248-252.

4. Keskinkılıç B, Engin-Üstün Y, Sanisoğlu S, Şahin Uygur D, Keskin HL, et al. (2017) Maternal mortality due to hypertensive disorders in pregnancy, childbirth, and the puerperium between 2012 and 2015 in Turkey: A nation-based study. J Turk Ger Gynecol Assoc 18(1): 20-25.

5. Guntupalli KK, Karnad DR, Bandi V, Hall N, Belfort M (2015) Critical Illness in Pregnancy: Part II: Common Medical Conditions Complicating Pregnancy and Puerperium. Chest 148(5): 1333-1345.

6. Mcllroy E, Sethuraman R, Woograsingh R, Nelson-Piercy C, GilbertKawai E (2017) Severe Postpartum Headache and Hypertension Caused by Reversible Cerebral Vasoconstriction Syndrome: A Case Report. A A Case Rep 9(10): 289-291.

7. Rezai S, Faye J, Hughes A, Cheung ML, Cohen JR, et al. (2017) Hemolysis, Elevated Liver Enzymes, and Low Platelets, Severe Fetal Growth Restriction, Postpartum Subarachnoid Hemorrhage, and Craniotomy: A Rare Case Report and Systematic Review. Case Rep Obstet Gynecol 2017: 8481290 .

8. Brousseau EC, Danilack V, Matteson K (2017) Emergency department visits for postpartum hypertension. Hypertens Pregnancy 36(2): 212216.

9. Beardmore KS, Morris JM, Gallery ED (2002) Excretion of antihypertensive medication into human breast milk: a systematic review. Hypertens Pregnancy 21(1): 85.

10. Sibai BM (2012) Etiology and management of postpartum hypertension-preeclampsia. Am J Obstet Gynecol 206(6): 470.

\section{Your next submission with Juniper Publishers} will reach you the below assets

- Quality Editorial service

- Swift Peer Review

- Reprints availability

- E-prints Service

- Manuscript Podcast for convenient understanding

- Global attainment for your research

- Manuscript accessibility in different formats

( Pdf, E-pub, Full Text, Audio)

- Unceasing customer service

Track the below URL for one-step submission https://juniperpublishers.com/online-submission.php 